\title{
2006-1459: A LESSON FROM HURRICANE KATRINA: MEETING THE NEED FOR COASTAL ENGINEERING IN THE GULF COAST REGION
}

\section{Qin Chen, University of South Alabama}

Dr. Qin "Jim" Chen, is an Assistant Professor of Civil Engineering and of Marine Science at the University of South Alabama, where he has been on the faculty since 2001. Before joining USA, Dr. Chen conducted post-doctoral research at the University of Delaware's Center for Applied Coastal Research and doctoral research at Old Dominion University as well as at the Danish Hydraulic Institute. He has taught five courses in Civil Engineering at USA. Dr. Chen specializes in the development and application of numerical models for coastal hydrodynamics, including surface waves, wave-induced nearshore circulation, storm surges, estuarine circulation, and sediment transport. His research has focused on water wave mechanics, Boussinesq modeling of surf-zone currents and the coupling of storm waves and surges. He is currently conducting sponsored research on the prediction of storm surges and wind waves in the Gulf of Mexico and on the coasts, wave forces on coastal bridges and roadways, numerical modeling of surf-zone currents, and prediction of circulation and sediment transport in shallow estuaries. His research has been funded by eight federal agencies, including the National Science Foundation (NSF), the Office of Naval Research and Federal Highway Administration. Dr. Chen is a recipient of the NSF CAREER Award and a member of ASEE, ASCE, AGU, and ACE. 


\title{
A Lesson from Hurricane Katrina: Meeting the Need for Coastal Engineering Education and Research in the Gulf Coast Region
}

\begin{abstract}
One of the important lessons from Hurricane Katrina (2005) is the pressing need for coastal engineering research and education along the Gulf Coast. There are 21 universities offering graduate programs in coastal engineering nationwide. However, most of the coastal engineering programs are located on the East and West Coasts. In fact, from the Florida Panhandle to the Louisiana-Texas boarder, there are no graduate programs in coastal engineering on the central Gulf Coast. The inadequate coastal engineering research and education in the Gulf Coast region are reflected in the failures of civil engineering infrastructure and buildings seen in the Hurricane Katrina's aftermath. We use the collapse of coastal bridges during Hurricane Katrina as an example to demonstrate the need for and importance of coastal engineering research and education in hurricane-prone areas. An examination of the engineering practice in the transportation engineering community has indicated transportation engineers often rely on coastal engineers to assist their design and construction of coastal highways because of the uniqueness of the coastal wave and water level environments. The absence of coastal engineering education programs in Louisiana, Mississippi and Alabama has limited access to the coastal engineering knowledge and expertise needed by the transportation engineering community in the three states. Meeting education and research needs in coastal engineering along the Gulf Coast is essential to the recovery and rebuilding the region devastated by recent hurricanes.
\end{abstract}

\section{Introduction}

Hurricane Katrina (2005) made landfall on the north coast of the Gulf of Mexico as a catastrophic storm. It devastated New Orleans, Louisiana, as well as the Mississippi and Alabama coasts, and its ripple effects impacted the entire nation. Hurricane Katrina is one of the deadliest and costliest natural disasters in U.S. history. The $30 \mathrm{ft}$ water surge generated by Katrina at landfall on the north Gulf Coast is the highest storm surge ever recorded in the United States $^{[1]}$.

Among the important lessons form Hurricane Katrina is the need for coastal engineering research and education along the Gulf Coast. Consistent with the survey conducted by the National Research Council in the late $1990 \mathrm{~s}^{[2]}$, there are 21 institutions offering graduate programs in coastal engineering nationwide. However, most of the coastal engineering programs are located on the East and West Coasts. In fact, from the Florida Panhandle to the Louisiana-Texas boarder, there are no graduate programs in coastal engineering in the central Gulf Coast. Although there 
are a few coastal science programs in this region, no university in the three states devastated by Hurricane Katrina has a graduate program focused on civil engineering in the coastal environment. The inadequate coastal engineering research and education in the Gulf Coast region are reflected in the failures of civil engineering infrastructure and buildings seen in the Hurricane Katrina's aftermath.

We use the collapse of coastal bridges during Hurricane Katrina as an example to demonstrate the need for and importance of coastal engineering research and education in hurricane-prone areas. Using state-of-the-art computer models, we have simulated the storm surge and wind waves generated by Hurricane Katrina. The model results are compared with field observations, including offshore buoy data of surface waves and post-storm survey of high watermarks. We then use the modeled waves and surges to explain the collapse and damage of several coastal bridges, including a bridge of Interstate Highway 10 (I10) and two bridges of U.S. Highway 90 (US90) in Mississippi. An examination of the engineering practice in the transportation engineering community has indicated that transportation engineers often rely on coastal engineers to assist their design and construction of coastal highways because of the uniqueness of the coastal wave and water level environments. The absence of coastal engineering education programs in Louisiana, Mississippi and Alabama has limited access to the coastal engineering knowledge and expertise needed by the transportation engineering community in the three states.

According to U.S. census data, more than $50 \%$ of the U.S. population lives within 50 miles of the shoreline and the coastal population continues to grow. The nation's nearshore regions are under severe stresses owing to increased human activities and climate change. Besides environmental issues, the continuing popularity of coastal areas and increased development along the coastlines put more people and property at risk from coastal hazards, as seen in the devastation of the 2004 and 2005 hurricane seasons. Mitigating the impacts of such coastal disasters requires adequate coastal engineering research and education in order to inform the public and decision-makers, facilitate the management of coastal resources and emergency response, and improve

engineering design of coastal infrastructure, shore protection devices and buildings. Meeting the pressing need for coastal engineering education and research in the Gulf Coast region is an important lesson from Hurricane Katrina (2005).

\section{Status of Coastal Engineering Education in the Gulf Coast Region}

Coastal engineering is a sub-discipline in civil engineering. It may be defined as civil engineering in the unique coastal environment, including the interface of land and water, bays, lakes, estuaries, inlets, and coastal oceans, where surface waves and varying water levels are often the driving force of many processes. The practice of coastal engineering involves not only the traditional civil engineering principles, but also the sciences of oceanography and coastal geology. The typical civil engineering curriculum of an undergraduate program, however, does not include course work in marine sciences and coastal engineering.

The discipline of coastal engineering in the United States began in the 1930s in connection mainly to oceanfront development and grew significantly during the Second World War in connection to naval operation and troop landing on the beach. Today, coastal engineers have 
expanded their role from the traditional port construction and shore protection to encompassing environmental and ecological issues in the unique coastal system ${ }^{[2]}$.

How many universities and colleges in the United States have coastal engineering programs? According to a survey conducted by the National Research Council (NRC) in the late 1990s ${ }^{\text {[2] }}$, there are 21 institutions offering graduate programs in coastal engineering nationwide. Figure 1 depicts the geographic distribution of the coastal engineering programs. It is seen that most of them are located on the East and West Coasts. Almost every coastal state on the East and West Coasts has at least a university with a graduate program in coastal engineering. However, from the Florida Panhandle to the Louisiana-Texas boarder, there are no graduate programs in coastal engineering in the central Gulf Coast. Although there are a few coastal science programs in this region, no university in the three states devastated by Hurricane Katrina has a graduate program focused on civil engineering in the coastal environment.

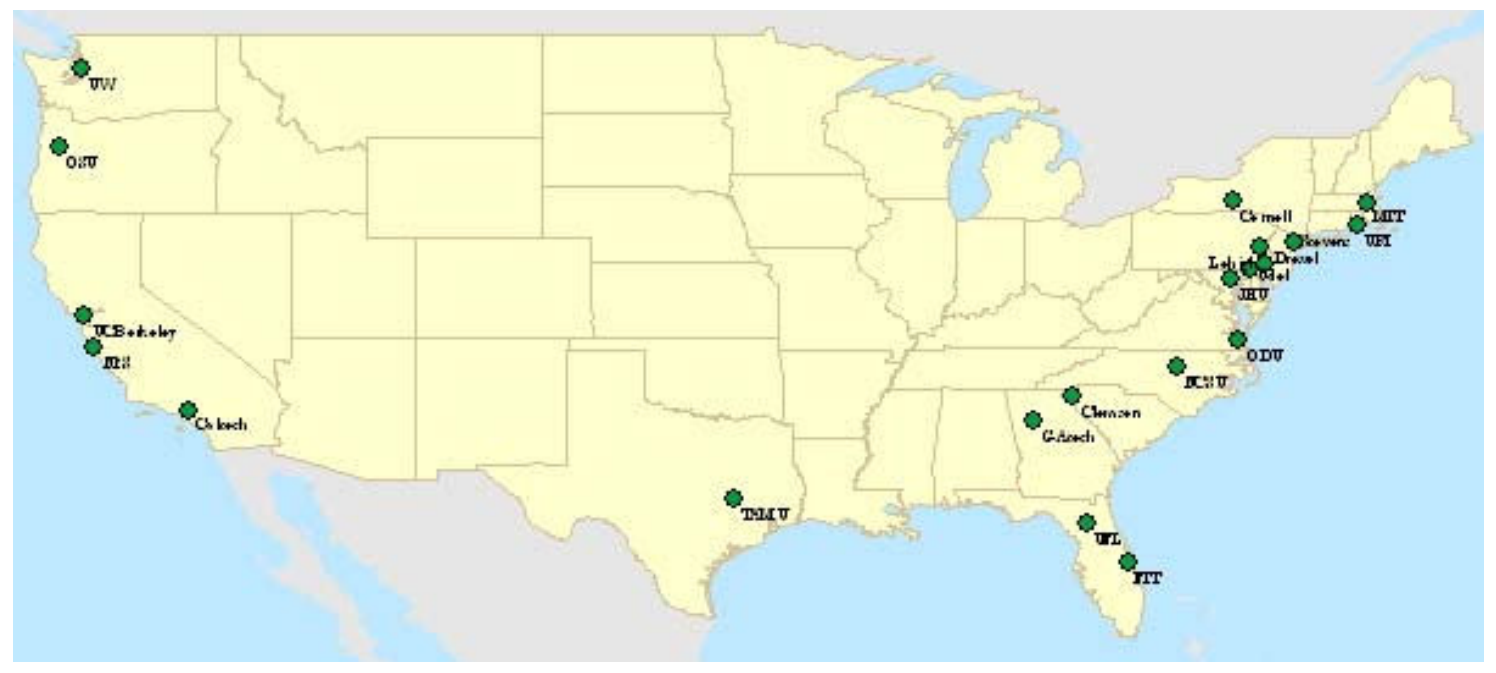

Figure 1. Geographic distribution of coastal engineering programs in the United States

Many questions arise after the devastation of Hurricane Katrina along the central Gulf Coast. Among them is whether the inadequate coastal engineering education and research in the Gulf Coast region are reflected in the failures of civil engineering infrastructure and buildings seen in the Hurricane Katrina's aftermath. Is there a pressing need for coastal engineering education and research in the three Gulf States impacted by the hurricane? What is the role of coastal engineers in the recovery and rebuilding of the devastated Gulf region? How can we avoid hurricane destruction to coastal infrastructure? We shall seek answers to those questions.

\section{The Cause of Coastal Bridge Collapse during Hurricane Katrina}

Katrina started as a tropical depression on August 23, 2005 in the Atlantic. It strengthened into a tropical storm the next day and became a Category 1 hurricane before it made its first landfall between Hallandale Beach and North Miami Beach, FL on August 25. After entering the Gulf of Mexico, Katrina continued to strengthen in the next several days because of the warm water 
temperature and favorable conditions in the Gulf. On Sunday, August 28, Hurricane Katrina reached Category 5 status with wind speeds of $175 \mathrm{mph}$ and a pressure of 902 millibars $^{[3]}$.

Katrina weakened a bit when it advanced toward Louisiana and made its second landfall between Grand Isle, LA and the mouth of the Mississippi River on the early Monday morning, August 29, as a Category 4 hurricane with wind speeds of $140 \mathrm{mph}$ and a low pressure of $920 \mathrm{mb}$. By 1000CDT (Central Daylight Time), Katrina made its third landfall near the Louisiana and Mississippi borderline as a Category 3 hurricane with wind speeds of nearly $125 \mathrm{mph}^{[3]}$.

Katrina caused widespread, catastrophic devastation along the central Gulf Coast. More than a quarter million people were displaced, more than 1,000 people lost their lives, and the property damage exceeded $\$ 100$ billion $^{[3]}$. Civil engineering infrastructure, including highways, roads, bridges and ports throughout the Gulf Coast in Louisiana, Mississippi and Alabama took a hard hit from Katrina. Among them are the two bridges on the U.S. Highway 90 in Mississippi and the bridge on the Interstate Highway 10 connecting New Orleans and Slidell, Louisiana.

Figure 2 shows the US90 bridge over Bolixi Bay, Mississippi, destroyed by Hurricane Katrina. Most of the bridge decks collapsed during Katrina. The costs of rebuilding all the coastal bridges damaged by Hurricanes Katrina (2005) and Ivan (2004) well exceed \$1 billion ${ }^{[4]}$.

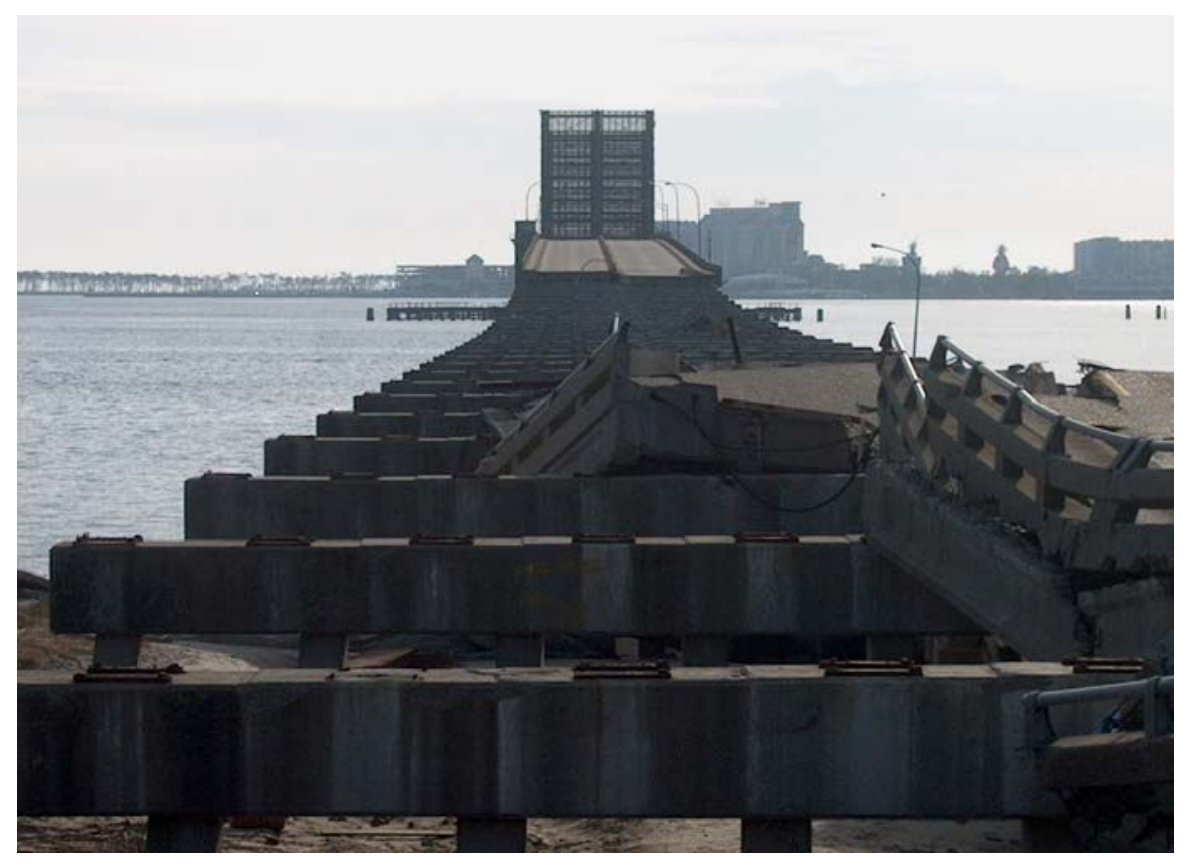

Figure 2. Failure of the US90 bridge crossing Biloxi Bay, Mississippi

As part of the research effort sponsored by the Federal Highway Administration (FHWA), we have investigated the cause of the coastal bridge failures using state-of-the-art computer models 
for storm surges and wind waves. Because all the tide and wave gages on the Mississippi coast malfunctioned, the goal of our study is to hindcast the detailed information on water surges and storm waves in the area devastated by Katrina in order to assist transportation engineers with the assessment of Katrina's destruction. By coupling the ADCIRC (ADvanced CIRCulation) surge model and the SWAN ( Simulation of WAves in Nearshore areas) wave model, we have simulated the storm surge and wind waves generated by Hurricane Katrina on the Mississippi and Alabama coasts. The wind fields for both surge and wave models were taken from different sources and parametric hurricane wind models, including the Hurricane Research Division's surface wind analysis data. We have developed an effective and reliable methodology for nesting and coupling the storm surge and wave models ${ }^{[5][6]}$.

The model results have been compared with field observations, including offshore buoy data of surface waves, tide gage data and post-storm survey of high watermarks. Generally good agreement is found ${ }^{[7]}$. Figure 3 shows the bottom topography and the coastlines in the northern Gulf of Mexico. The combination of strong winds, shallow water depth and the funneling effect of the coastal geometry resulted in the highest storm surge ever recorded in the United States.

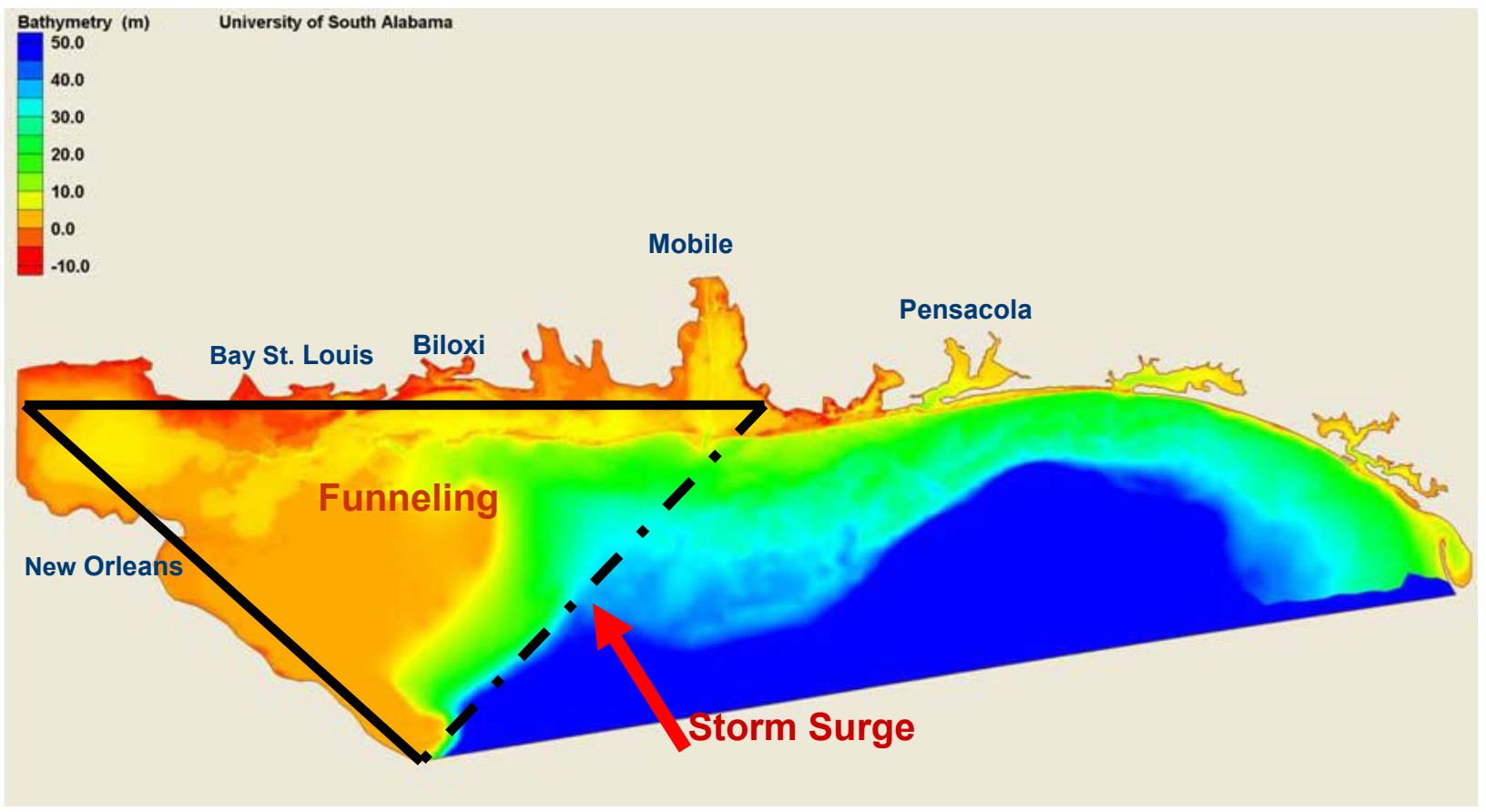

Figure 3. Bottom topography and coastal geometry of the northern Gulf of Mexico

Figure 4 shows the flood map of the maximum surge predicted by the storm surge model. It is seen that the highest surge reached $10 \mathrm{~m}$ above the mean sea level (MSL), as reported in the post-storm survey. By coupling the storm surge model with the wind wave model, we are able to predict the hurricane waves riding on the storm surge, as illustrated in Figure 5. 


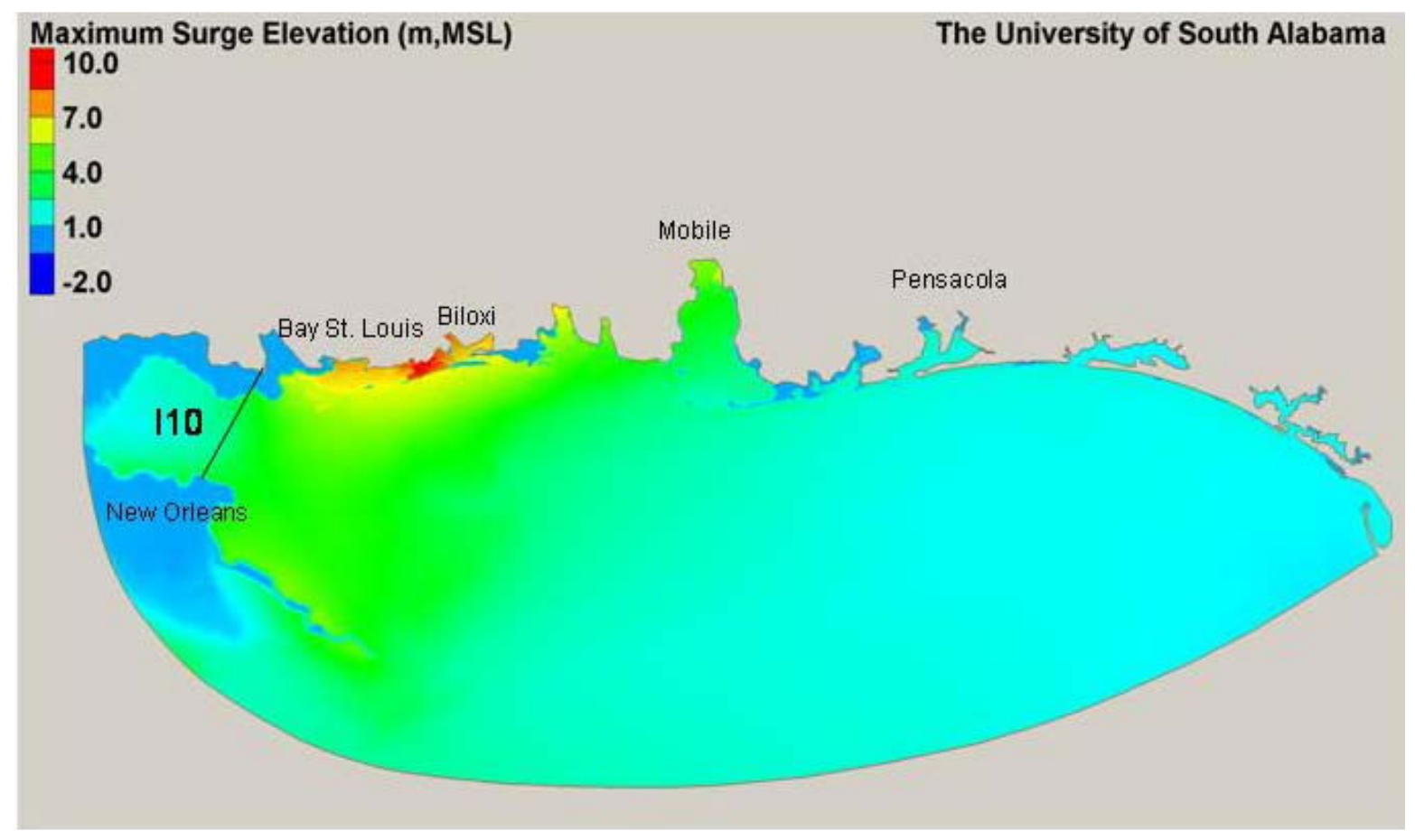

Figure 4. Maximum surge heights predicted by the storm surge model

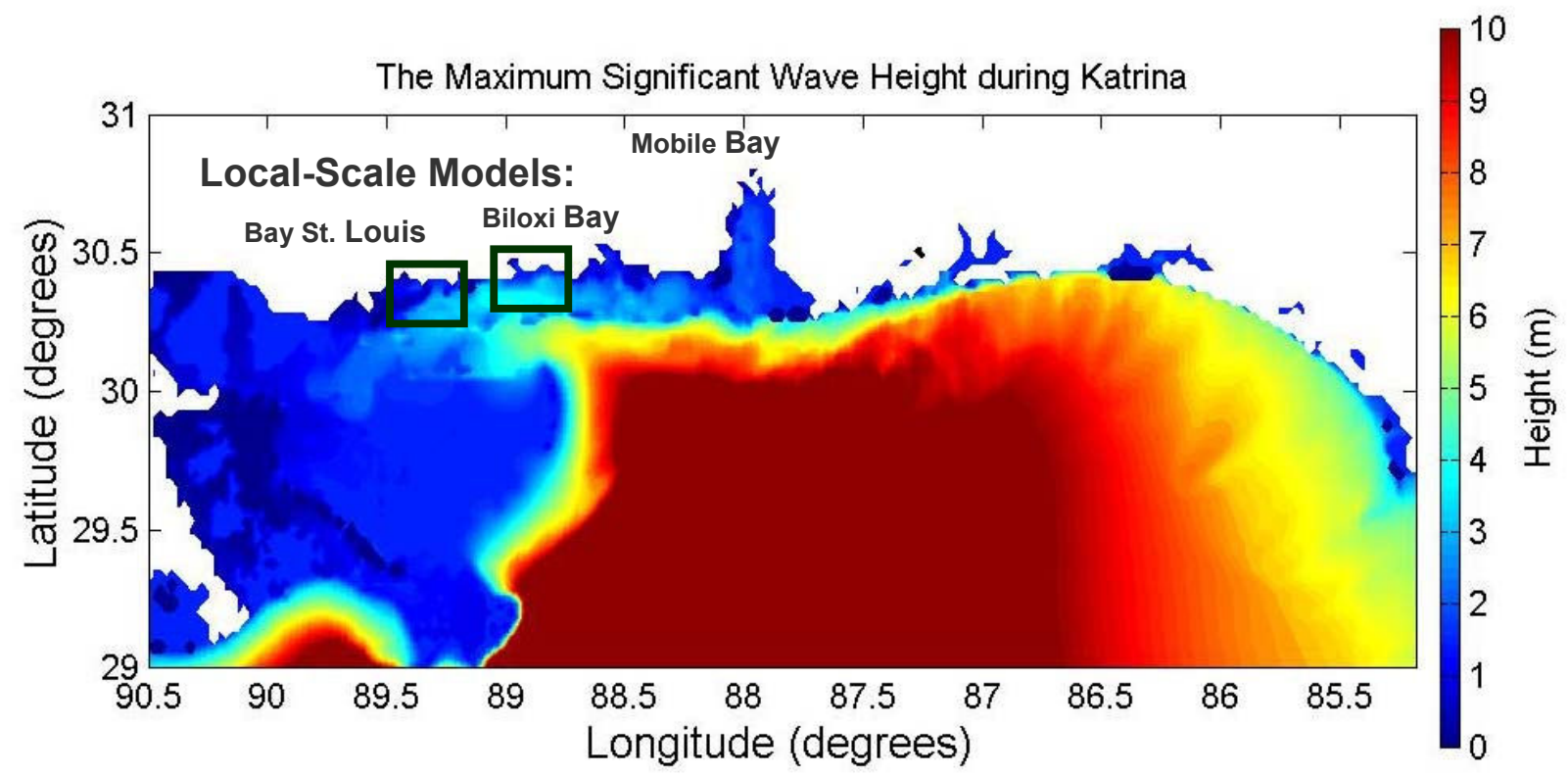

Figure 5. Maximum significant wave heights predicted by the coupled surge and wave modeling system 
We then use the modeled waves and surges to explain the collapse and damage of several coastal bridges, including one bridge on Interstate Highway 10 and two bridges of U.S. Highway 90 along the Mississippi coast ${ }^{[6]}$. The predicted surge and wave conditions near the bridges allow us to estimate the wave slamming and uplifting forces on the bridge decks, as illustrated in Figure 6. Unfortunately, such wave forces were not considered by transportation engineers. The methodologies we have developed can be utilized to evaluate the vulnerability of coastal bridges in hurricane-prone areas and improve the design of coastal transportation infrastructure. The model results of Katrina's surges and waves are useful for rebuilding the north Gulf Coast.

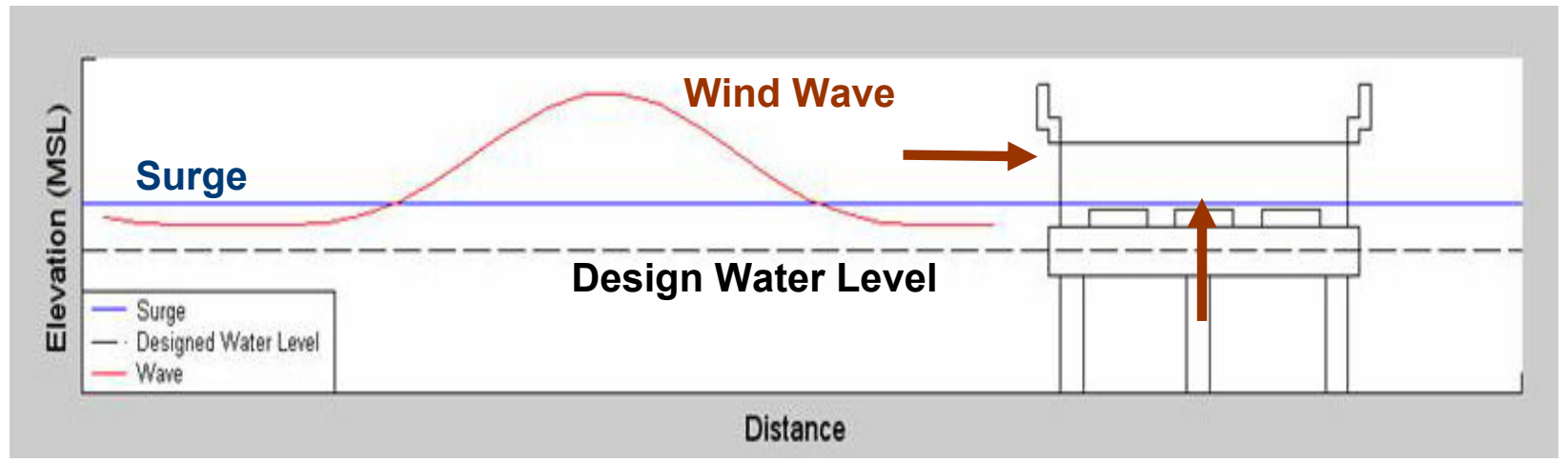

Figure 6. Schematic of wave forces on a coastal bridge.

\section{Meeting Education and Research Needs in Coastal Engineering}

More than $50 \%$ of the U.S. population lives within 50 miles of the shoreline. This number is expected to increase to $60 \%$ by the end of this decade ${ }^{[2]}$. Besides environmental issues, the continuing popularity of coastal areas and increased development along the coastlines put more people and property at risk from coastal hazards. Mitigating the impacts of coastal disasters requires adequate coastal engineering research and education in order to inform the public and decision-makers, facilitate the management of coastal resources and emergency response, and improve engineering design of coastal infrastructure, shore protection devices and buildings. The National Research Council's study published in 1999 has pointed out the important role of coastal engineering to the vitality of the nation's shorelines and coastal infrastructure. Three specific recommendations were made by the NRC committee in order to meet education and research needs in coastal engineering in the United States ${ }^{[2]}$.

1. The committee recommends that the coastal engineering academic community establish a consortium to improve research and education through cooperative arrangements for leveraging major research facilities and educational capabilities. 
2. The committee recommends that the National Science Foundation establish a program in its Engineering Division to fund fundamental research on coastal engineering.

3. The committee recommends that the U.S. Army Corps of Engineers establish a substantial program to fund applied research in academic coastal engineering programs.

Unfortunately, those recommendations have not been adopted by the federal agencies and academic institutions. Hurricane Katrina taught us the vital role of coastal engineering again.

In the aftermath of Hurricane Katrina, the Federal Highway Administration realized that the vulnerability of coastal bridges to wave attack has been elevated to a pressing, national issue. A national symposium on "Wave Forces on Coastal Bridges" was held in Mclean, Virginia in December 5-7, 2005. The Departments of Transportation (DOT's) from most of the coastal states participated in the symposium. Coastal engineering researchers from several universities, including Texas A \& M University, the University of Florida, Old Dominion University, the University of Delaware, Oregon State University, the U.S. Naval Academy, and the University of South Alabama, were invited by the FHWA to participate in the symposium. In addition, engineers in consulting firms specialized in coastal engineering also attended the conference. The FHWA has recognized that typical transportation engineers have not been trained to design coastal roadways and bridges in the unique coastal environment. They have to rely on the expertise of coastal engineers.

Although the transportation infrastructure in Louisiana and Mississippi suffered the most damage from Hurricane Katrina, none of the universities in both states was able to participate in the FHWA-sponsored symposium. There are coastal science programs in Louisiana and Mississippi, but there are no coastal engineering programs at universities in both states. In fact, the DOT's in both states have to contract coastal engineering consulting firms in other states to assist them in the assessment of the damage and repairs of the failed bridges.

By contrast, Florida DOT has relied on the coastal engineering expertise at the University of Florida and other state-supported colleges to assist them with the analyses of storm surges, wind waves, and sediment transport over the last decade ${ }^{[4]}$. As an example, Hurricane Ivan (2004) damaged an I-10 bridge crossing Escambia Bay in Florida. The active coastal engineering research and education programs in Florida have played a significant role in the assessment, repairs and redesign of the failed bridge.

Recognizing the growing, national need for research and education focused on highways in the coastal environment, the University of South Alabama has established a Coastal Transportation Engineering Research and Education Center (CTEREC) recently. The Center is funded by the Federal Highway Administration. Research activities at the Center are focused on the design of technologically sound and environmentally friendly solutions to future transportation needs including, but not limited to, roadway design for survivability and storm water runoff management in areas that are occasionally exposed to coastal storm surge ${ }^{[8]}$. The CTEREC is taking a leading role in synthesizing the state-of-the-art knowledge of wave forces on piers and decks as well as developing guidelines on how to estimate wave forces on bridge decks. 
Obviously, the need for coastal engineering research and education is not just limited to the transportation engineering community. As pointed out by Douglass ${ }^{[9]}$, we must, and we can engineer our buildings, roads, ports and other critical parts of society along the coast to survive major hurricanes by using modern coastal engineering principles.

As part of the efforts to meet the need for coastal engineering in the Gulf Coast region, the Department of Civil Engineering at the University of South Alabama (USACE) is in the process of establishing a unique graduate program in civil engineering with an emphasis in the coastal environment. The new program will serve the U.S. Gulf Coast and beyond. In addition, the USACE is collaborating with the Department of Civil and Environmental Engineering at Old Dominion University (ODUCE) to establish a Cooperative Doctoral Program in Civil Engineering with a specialty in Coastal Engineering (CPhDCE). The USACE has active research programs with two faculty members specialized in coastal engineering in the absence of a doctoral program. The ODUCE has a well-established Ph.D. grogram offering online graduatelevel courses in coastal engineering. A cooperative, doctoral-level, educational and research program complements the strength of both parties. Such high-level, intra-university collaborations are in the best interests of both universities and in the spirit of the first recommendation made by the $\mathrm{NRC}^{[2]}$.

With the support from the National Science Foundation (NSF), the USACE is also developing an outreach curriculum entitled "Introduction to the coastal environment" at three levels: the general public and high-school students, sixth-twelve grade math and science teachers, and practicing civil engineers ${ }^{[10]}$. The integrated educational program from K-12 to graduate studies will enhance ocean-related education and attract K-12 students to the field of ocean science in general and to the profession of coastal engineering in particular. The need for such an integrated program has been specifically emphasized by the U.S. Commission on Ocean Policy in 2004, the National Research Council in1999, and the National Science Board in 2004. Hurricane Katrina (2005) has shown the urgency and importance of establishing and enhancing coastal engineering education in the hurricane-prone Gulf Coast region.

\section{Summary and Conclusions}

One of the lessons from Hurricane Katrina (2005) is the pressing need for coastal engineering research and education along the Gulf Coast. A survey has shown that there are 21 universities offering graduate programs in coastal engineering nationwide. However, most of the coastal engineering programs are located on the East and West Coasts. In fact, from the Florida Panhandle to the Louisiana/Texas boarder, there are no graduate programs in coastal engineering on the central Gulf Coast. The inadequate coastal engineering research and education in the Gulf Coast region are reflected in the failures of civil engineering infrastructure and buildings seen in the Hurricane Katrina's aftermath.

We use the collapse of coastal bridges during Hurricane Katrina as an example to demonstrate the need for and importance of coastal engineering research and education in hurricane-prone areas. An examination of the engineering practice in the transportation engineering community has revealed that transportation engineers often rely on coastal engineers to assist their design and construction of coastal highways because of the uniqueness of the coastal wave and water 
level environments. The absence of coastal engineering research and education programs in Louisiana, Mississippi and Alabama has limited access to the coastal engineering knowledge and expertise within the three states. Meeting education and research needs in coastal engineering along the Gulf Coast is essential to the recovery and rebuilding the region devastated by recent hurricanes. Efforts are being made at the University of South Alabama and Louisiana State University. It is vital that state and federal governments adopt the National Research Council's recommendations to increase funding for coastal engineering.

\section{Acknowledgments}

Support for the research has been provided by the Federal Highway Administration, the U.S. Fish and Wildlife Service, and the National Science Foundation. Discussions with Professors S. L. Douglass and D. R. Basco as well as assistance from Ms. L. Wang are sincerely acknowledged.

Bibliography

1. Bossak, B. H., Katrina's wake, EOS, American Geophysical Union, Vol. 86: 27, 333-334, 2005.

2. National Research Council. Meeting Research and Education Needs in Coastal Engineering, National Academy Press. Washington, D.C., 1999.

3. Graumann, A., Houston, T., Lawrimore, J., Levinson, D., Lott, N., McCown, S., Stephens, S., and Wuerts, D. Hurricane Katrina: A Climatological Perspective - Preliminary Report, Technical Report 2005-01, NOAA's Nationa Climate Data Center, 2005.

4. Nickas, W. N., Renna, R., Sheppard, N., and Mertz, D. R., Hurricane-based wave attacks, Florida Department of Transportation, 2005

5. Chen, Q., Zhao, H., Hu, K, and Douglass, S. L, Prediction of wind waves in a shallow estuary. Journal of Waterway, Port, Coastal and Ocean Engineering, 131 (4): 137-148, 2005.

6. Chen, Q., How to determine surge and wave conditions near coastal bridges, National Symposium on Waves Forces, Federal Highway Administration, 2005.

7. Chen, Q., Wang, L., and Zhao, H., Simulation of storm surges and wind waves on the Mississippi and Alabama coasts during Hurricane Katrina, AGU Ocean Sciences Meeting, Honolulu, Hawaii, February 2024, 2006.

8. The University of South Alabama, Coastal Transportation Engineering Research and Education Center, http://www.southalabama.edu/usacterec/research.html

9. Douglass, S. L. We have to do better, Mobile Register, September 11, 2005

10. Chen, Q., Simulations of nonlinear water waves and air-to-sea momentum fluxes in the coastal ocean, Faculty Early Career Development Award from the National Science Foundation, February 10, 2006. http://www.nsf.gov/awardsearch/showAward.do?AwardNumber=0547056 